\title{
SINGULARIDADES DA INSERÇÃO PROFISSIONAL DE PROFESSORES DE EDUCAÇÃO FÍSICA INICIANTES
}

\author{
SINGULARITIES OF PROFESSIONAL BEGINNING OF PHYSICAL EDUCATION \\ TEACHERS
}

\author{
"LAS SINGULARIDADES DE LA INSERCION PROFESIONAL DE LOS \\ PROFESORES DE EDUCACIÓN FÍSICA PRINCIPIANTES
}

\author{
José Angelo Gariglio*
}

Palavras chave: Capacitação de professores.

Ensino.

Educação Física

Escolar.

Keywords:

Teacher training

Teaching.

Physical education
Resumo: Este artigo relata os achados de uma pesquisa que trata dos aspectos singulares dos processos de iniciação à docência de 13 professores de Educação Física formados pela UFMG. A metodologia é de caráter qualitativo e faz uso de apenas uma técnica de coleta de dados: a entrevista semiestruturada. Os dados da pesquisa mostram que o pertencimento a um determinado campo disciplinar é um elemento importante a considerar para análise de diferentes trajetórias percorridas pelos professores no período da iniciação à docência, já que definem modos cruciais de ser professor e de inserir na profissão.

Abstract: This article reports on the findings of a study that addresses the unique aspects of teaching initiation processes for 13 Physical Education teachers graduated at UFMG. The methodology is qualitative and uses only one data collection technique: semi-structured interviews. The survey's data show that belonging to a particular disciplinary field is an important element to be considered for the analysis of teachers' distinct trajectories in the period of their professional initiation, since they establish crucial ways of being a teacher and entering the profession.

Resumen: En este artículo se presentan los resultados de una investigación que se ocupa de los aspectos únicos de iniciación a la docencia de 13 profesores de Educación Física graduados por la UFMG. La metodología es cualitativa y hace uso de una sola técnica de recolección de datos: la entrevista semiestructurada. Los datos de la investigación muestran que la pertenencia a un campo disciplinario particular es un elemento importante a tener en cuenta para el análisis de diferentes trayectorias recorridas por los maestros en el periodo de iniciación a la docencia, ya que establecen formas cruciales de ser maestro y de inserirse en la profesión.
*Universidade Federal de Minas Gerais. Belo Horizonte, MG, Brasil. E-mail: gariglioja@gmail.com

Recebido em: 17-03-2017 Aprovado em: 10-07-2017 


\section{INTRODUÇÃO}

Nos últimos trinta anos, parte das literaturas internacional e nacional que tratam da formação de professores vem buscando compreender melhor os processos de socialização e desenvolvimento profissional dos docentes. Tais estudos visam, entre outros objetivos, compreender de que maneira os professores dão sentido a sua vida profissional e de que forma se entregam a ela como atores cujas ações e projetos contribuem para definir e construir sua carreira. Esse processo de modelação da carreira docente, entendida como a confluência entre a ação dos indivíduos e as normas e papéis que decorrem da institucionalização das ocupações, estabelece formas de ser, agir e pensar que os indivíduos devem interiorizar e dominar para fazer parte da profissão docente.

Vários autores no campo dos estudos sobre a formação de professores têm tratado a carreira docente como um contínuo formativo marcado pela presença de ciclos ou fases de desenvolvimento profissional. Huberman (1992), ao construir reflexões sobre essa hipótese, levanta questões que, para ele, ainda precisam ser debatidas de forma mais consistente. Dentre essas, destacamos três que expressam mais claramente 0 que os estudos sobre os ciclos de desenvolvimento profissional de professores almejam conhecer mais de perto: será que todos os professores passariam pelas mesmas etapas, as mesmas crises, os mesmos acontecimentos, o mesmo termo de carreira, independentemente da geração a que pertencem, ou haverá percursos diferentes, de acordo com o momento histórico da carreira? Que imagem essas pessoas têm de si, como professores, em situação de sala de sala de aula, em momentos diferentes da sua carreira? Esses docentes terão a percepção de que transformam os seus processos de animação, a sua relação com os alunos, a organização das aulas, as suas prioridades ou o domínio da matéria que ensinam?

$\mathrm{Na}$ busca por construir respostas sustentáveis a esses questionamentos, alguns pesquisadores vêm tentando nomear ou classificar quais seriam e como se caracterizariam os diferentes ciclos de vida profissional dos professores. Carter et al. (1987) propõem um modelo no qual os professores experimentariam cinco fases distintas na carreira docente: professor iniciante; iniciante avançado, prático competente, prático proficiente e o professor expert. Feiman-Nemser (2001) aponta que o processo de aprendizagem profissional, por sua vez, inclui três fases: a formação inicial, a indução (fase de transição entre a formação inicial e a entrada na profissão) e o desenvolvimento profissional. Vonk (1993) propõe que a carreira docente seria dividida em duas distintas fases, a saber: a de entrada na profissão e a de crescimento na profissão. A fase de entrada diz respeito ao primeiro ano de trabalho na escola, durante 0 qual os novos professores são confrontados pela primeira vez com as múltiplas responsabilidades do ato de ensinar. Já a fase de crescimento na profissão é caracterizada pela aceitação de professores iniciantes pelos seus alunos e por colegas. Durante esse período, os novos professores tendem a centrar a sua atenção na melhoria das competências, nos métodos e nas competências.

O encontro com a realidade profissional é muitas vezes descrito na literatura em termos duros, como de crise com a profissão, como uma espécie de "batismo de fogo" (KELCHETERMANS; BALLET, 2002). A entrada na profissão é designada também como "choque de realidade" (HUBERMAN, 1992) e "choque de transição" (VEENMAN, 1984). Tais termos são utilizados para referir à situação que muitos professores vivem nos primeiros anos de docência e que corresponde ao impacto sofrido da experiência de contato inicial com o meio 
socioprofissional e de ruptura da imagem ideal de ensino, o colapso das ideias missionárias forjadas durante a formação dos professores, em virtude da dura realidade de ter que lidar com desafios oriundos da vida quotidiana na sala de aula, da relação com os pais, com os pares, com a diversidade dos alunos e suas dificuldades de aprendizagem e com a falta de recursos e apoio da comunidade escolar. Em alguns casos, esse período traumático se estende por mais ou menos tempo; isso dependerá da assimilação e da compreensão da realidade complexa que o professor tem de enfrentar (VEENMAN, 1984).

Não obstante constatar na produção teórica certas diferenças na definição e denominação dos diferentes ciclos de desenvolvimento profissional docente, em um ponto específico a literatura sobre o tema tem manifestado certo consenso: de que a iniciação à docência é um período singular da trajetória docente e potencialmente determinante na construção da história profissional dos professores, atuando de forma a influir no tipo de relação a ser estabelecida com o trabalho, seja no presente, seja no futuro. Mesmo reconhecendo a premissa de que a iniciação à docência é um momento singular da carreira docente e que os professores iniciantes vivem experiências profissionais que seriam similares, há que se levar em consideração que tal experiência não pode ou não deveria ser tomada como algo absoluto. Como se todos os professores, independentemente do contexto sociocultural do país de origem, das características dos sistemas nacionais de ensino, do tipo de experiência na formação inicial, da escola onde atuam, do nível de ensino no qual lecionam, da disciplina escolar a qual pertencem, da sua condição de gênero, experimentassem os mesmos obstáculos de sobrevivência e as mesmas possibilidades de descoberta da profissão.

Os estudos de cunho sociológico, ao se contraporem à perspectiva psicológica do ciclo da vida, colocam-se críticos à ideia de que as sequências da vida seriam predeterminadas e invariáveis, que todos os professores passariam pelas mesmas fases, dentro de uma mesma ordem, independentemente das condições de formação e trabalho. Diferentemente desse modelo de causalidade, a abordagem sociológica tem apontado que a organização profissional é que cria, arbitrariamente, as condições de entrada, empenhamento, promoção e que confere sentido às fases de desenvolvimento da profissão (HUBERMAN, 1992).

Feiman-Nemser et al. (1984), em artigo em que realizam densa revisão teórica no campo dos estudos sobre a formação de professores, criticam a crença reconfortante da existência de uma cultura docente comum. Para eles, a suposição da existência de uma uniformidade cultural na docência é insustentável. Os autores defendem a tese de que, no campo de atuação profissional, convivem não apenas uma, mas várias culturas docentes. Isso porque os professores se diferem em idade, experiência, origem social, bagagem cultural, gênero, nível de ensino em que atuam, tipo de escola onde são lotados e o pertencimento a um campo disciplinar específico. Nesses diferentes contextos nos quais a profissão docente se desenvolve, forjar-se-iam culturas docentes diversas mediante o contato dos docentes com normas e interações sociais provenientes dos distintos contextos de atuação profissional. Dada a diversidade dos sujeitos e das formas de inserção profissional, os professores desenvolveriam "culturas profissionais" múltiplas, ou seja, um conjunto de sentimentos partilhados, de hábitos mentais, crenças profissionais e de modelos distintos de interação com os alunos, os colegas, os administradores e os parentes.

Segundo eles, as normas e as interações conformam estilos peculiares de como os docentes percebem seu trabalho, a forma como veem suas relações com os alunos, com outros 
professores, com os administradores da escola, com os pais. O cumprimento dessas normas e a interação estabelecida teriam variações entre os diferentes grupos de professores e a produção variada de recompensas intrínsecas e extrínsecas associadas ao exercício do métier profissional. Recompensas extrínsecas são os benefícios públicos como salários dignos, horas de trabalho, status elevado e poder. Recompensas intrínsecas são as recompensas psíquicas, subjetivas, são os aspectos do trabalho valorizados e visíveis aos olhos dos professores. Tais recompensas intrínsecas seriam a constatação, por parte dos docentes, de que seus alunos estão aprendendo, de que há ligação emocional estabelecida com os estudantes, interação com os colegas, satisfação em realizar um serviço valioso e gozo em promover atividades de ensino. Tomando esse debate como referência geradora do nosso estudo, pareceu-nos relevante investigar a iniciação à docência de professores vinculados a um determinado contexto disciplinar: a EF. Com esse recorte de estudo, buscamos encontrar respostas às seguintes questões: qual a relação entre a iniciação à docência e a especificidade pedagógica da Educação Física? A condição de professores de EF constitui um elemento importante à experiência de iniciação à docência? Quais seriam os principais desafios enfrentados pelos professores de Educação Física iniciantes?

\section{METODOLOGIA}

\subsection{Os sujeitos e o campo da pesquisa}

A pesquisa foi realizada com 13 licenciados (quatro homens e nove mulheres) formados pela Escola de Educação Física, Fisioterapia e Terapia Ocupacional da UFMG (EEFFTO), que tinham, no momento da realização da pesquisa, até dois anos de experiência com a docência em EF na escola. A escolha desses sujeitos de pesquisa foi aleatória, respeitando somente os critérios de tempo de experiência profissional na escola (todos teriam que ter no máximo de três anos de trabalho na escola) e serem formados em uma única instituição. A opção por trabalhar com docentes formados apenas em uma única instituição teve como objetivo a produção de análises que visassem estabelecer relações mais críveis entre o currículo da formação inicial e sua repercussão ante os desafios colocados pelas situações de trabalho próprias de contexto de iniciação à docência em Educação Física na escola e entender de que forma a experiência da iniciação à docência em Educação Física poderia ajudar a iluminar nossa leitura sobre os limites e possibilidade da formação inicial frente o contexto da inserção profissional neste campo disciplinar.

\subsection{Entrevistas}

A entrevista, de caráter semiestruturado, foi construída levando em consideração quatro eixos aglutinadores: a percepção sobre a iniciação à docência; as ações e estratégias pensadas e realizadas pelos professores com vistas ao enfrentamento da realidade e as aprendizagens docentes mais significativas e a relação entre a formação inicial e a iniciação à docência. Com as entrevistas, buscamos respostas para duas questões: como os professores se apercebem da situação precisa perante a qual se encontram nesse momento da carreira? Como esses docentes pensam e agem mediante a experiência de iniciar a docência no campo da intervenção pedagógica em EF? 


\subsection{Sobre a análise dos dados}

Ao desenvolvermos o trabalho de análise dos dados coletados na pesquisa, buscamos identificar o que os professores nos disseram sobre o que seria própria da experiência de iniciar a profissão na condição de docente vinculado ao campo da Educação Física Escolar. A tentativa de tradução da complexidade dessas experiências em discursos sobre essas mesmas experiências revelam que, sob alguns aspectos, a iniciação à docência dos nossos sujeitos de pesquisa é percebida de forma singular. Tal percepção estaria vinculada ao enfrentamento de desafios didáticos ligados ao contexto de ensino da EF e ao conjunto de expectativas (geralmente baixas) criadas pela comunidade escolar acerca do papel a ser cumprido por esta disciplina no currículo escolar.

Um primeiro dado que emerge do material empírico coletado diz respeito aos conflitos e às tensões geradas na relação dos professores com os alunos. Mais especificamente, na difícil negociação dos conteúdos a serem ensinados. Se em outras disciplinas escolares essa margem de negociação mostra-se mais restrita, dadas as formas de controle e regulação do conhecimento escolar geradas pelas pressões do mundo profissional, do Estado, dos gestores e dos pais, na EF os professores se deparam com um contexto um pouco diferente. Sobre os professores de EF, não recaem a mesma intensidade prescritiva e/ou mesmo tipo administração sobre o que, como e quando se ensina. Ao mesmo tempo em que ostentam maior autonomia na definição de seus projetos curriculares, os nossos sujeitos de pesquisa se veem fortemente pressionados (regulados) pelos estudantes. Estes últimos tencionam o diálogo para que os seus gostos e desejos imediatos sejam levados a efeito.

Nesse quadro, os professores se veem frágeis, primeiro porque os conhecimentos de que tratam a EF (as práticas corporais de movimento) têm relação direta com o mundo cotidiano ou com as práticas socais de referências ${ }^{1}$ (experiência midiática, tempo de lazer, vivências comunitárias). Com isso, os estudantes acabam tendo uma relação de maior intimidade e domínio no que concerne aos conteúdos de ensino objeto de seleção e tratamento pedagógico pela EF. Sendo assim, chegam à escola com experiências e preferências já inicialmente estruturadas e vão cobrar dos professores de EF que esses os satisfaçam de forma imediata.

Os professores de EF pesquisados (tais como os outros docentes das demais disciplinas) intencionam imprimir um ensino que garanta aos alunos o acesso a uma pluralidade de conteúdos que seriam próprios dessa disciplina escolar (danças, esportes, lutas, ginásticas, jogos, brinquedos e brincadeiras), e os alunos (pelo menos sua maioria), ao contrário, desejam e pressionam esses professores por um ensino restrito a um conteúdo (o esporte). Aqui surge uma das rupturas com a imagem idealizada de ensino forjada durante a formação dos professores, as quais os professores iniciantes de EF precisam rapidamente tentar harmonizar. $O$ relato abaixo expressa esse conflito vivido pelos nossos sujeitos de pesquisa:

Uma coisa que me chateia mais é essa relação com os alunos, principalmente do $9^{\circ}$ ano, questão da indisciplina, e dessa falta de interesse por alguns conteúdos, porque os alunos não entendem ainda que a Educação Física é muito mais do que os esportes, e a gente quer mostrar isso pra eles o tempo todo, trazer coisa nova, e justamente pra eles experimentarem as diferentes possibilidades que têm dentro das aulas e eles não conseguem perceber isso, entender e desconstruir

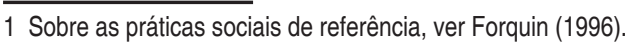


esse pensamento que a Educação Física seria só esportes. Eu acho que tem o problema também que eu falei dos alunos, quando eles não reconhecem a aula de Educação Física como uma aula que você pode ter muito mais do que esportes, então a gente tem que conversar muito com os alunos, a gente tem que mostrar para eles que a Educação Física é muito mais que esporte; então, é um trabalho um pouco cansativo ficar o tempo todo, ainda mais que a escola não tinha essa cultura desses conteúdos diferentes do esporte, e a gente tem que ficar martelando, a gente tem que ficar tentando desconstruir esse pensamento pra construir outra visão da Educação Física (Profa. 12).

Sobre esse tensionamento vivido pelos professores, penso ser importante lembrar duas questões fundamentais que estabelecem conexão direta com essa realidade vivida pelos professores de EF. A primeira diz respeito ao fato de que o esporte na sociedade moderna, pós-II Guerra Mundial, tornou-se uma prática corporal hegemônica, dotada de unanimidade/ positividade quase que inquestionável. Adultos, jovens e crianças são bombardeados diariamente por um conjunto avassalador de informações sobre o universo esportivo e de apelos à prática esportiva. Nesse contexto, a Educação Física torna-se sinônimo de esporte e viceversa. Esse fenômeno tem sido denominado pela literatura de esportivização da EF (BETTI, 1991). Esse poder de veiculação do esporte pode ser explicado pelo tipo de relação assumida entre o Estado e a sociedade civil em determinada época ou sociedade. Os interesses do Estado ao intervir na organização esportiva são os mais variados, uma vez que vão desde a "integração nacional", "a educação cívica", "a preservação da saúde da população", "a melhoria da qualidade de vida" e "o oferecimento de oportunidades de lazer". Segundo, porque o esporte de âmbito internacional, mais que uma genuína representação da capacidade esportiva da nação, encontra-se fortemente orientado pelos interesses do mercado esportivo, seus lucros, alguns monopólios e pela capacidade de pressão (LINHALES, 1996; BRACHT, 1997).

O peso das tensões geradas nesse conflito narrado pelos professores pode ser creditado em parte à falta de apoio da gestão escolar ao trabalho desenvolvido pelos professores de EF, quando esses formulam projetos pedagógicos que rompem com a lógica da esportivização. Para os professores de EF esta tarefa didática coloca-se como um dos principais desafios profissionais a superar; enquanto para a comunidade escolar tal empreitada se apresenta como algo pouco relevante. Essa baixa expectativa em relação ao ensino da EF acaba por inibir o desenvolvimento de ações de apoio e respaldo pedagógico que esses docentes necessitam ante 0 enfretamento dos conflitos gerados na relação entre professores e alunos, quando da definição dos conteúdos a serem ensinados nessa disciplina.

Sobre essa questão vale ressaltar que a inserção atual dessa disciplina na vida das escolas é, na maioria dos casos, potencialmente geradora de manifestações de desrespeito a ela e aos seus professores. As pesquisas vêm mostrando que a visão (e as ações) que os demais agentes escolares têm da EF, particularmente, diretores e demais professores, justifica que ela seja entendida como uma "disciplina de segunda classe". A atual cultura escolar de Educação Física está fortemente permeada por essa condição. Tal realidade incide, portanto, diretamente na vida dos seus professores, uma vez que esses acabam desenvolvendo uma compreensão de si como docentes também de "segunda classe", pelo menos numa posição inferior aos professores das demais disciplinas escolares (BRACHT; FARIA, 2010).

Em um cenário no qual as relações de poder e autoridade se mostram diluídas e a presença de estruturas de regulação e controle do conhecimento no ensino da EF, mais brandas, 
os professores dessa disciplina experimentam sensação de maior exposição emocional e insegurança profissional. Nessa realidade, convencer e "dobrar" a quem se ensina torna-se uma tarefa muito desgastante, sobretudo para professores iniciantes, que ainda carecem de estratégias, rotinas e referentes pedagógicos e didáticos mais estruturados que os orientem na difícil arte de persuadir os estudantes.

O outro lado desse dilema profissional são as conquistas relacionadas ao ensino de conteúdos que rompem com a lógica monodisciplinar. Tal experiência, que pode parecer corriqueira para um professor de outra disciplina escolar, é para o sujeito de nossa pesquisa elemento gerador de recompensas intrínsecas que alimentam a percepção da autoeficácia docente, o compromisso, a motivação e a satisfação com o trabalho. Sobre isso, Cochran-Smith (2006) aponta que muitas das pessoas que entram na atividade do ensino decidem por sair ou ficar na profissão. O compromisso com a aprendizagem e com a melhoria de oportunidades de vida de seus alunos nas escolas é o que, muitas vezes, fundamenta essa escolha e a decisão de permanecer na docência. A vivência não satisfatória de apoio da comunidade escolar, o fracasso contínuo no desenvolvimento de projetos de ensino e as tensões provenientes da relação com os alunos podem criar um ambiente de trabalho propício ao desinvestimento profissional e, por via de consequência, ao abandono precoce da profissão (MARIT ULVIK; KARI SMITH; INGRID HELLEVE, 2009). O relato a seguir ilustra bem essa afirmação.

Igual na aula de dança que a gente deu outro dia, foi um chororô danado pra fazer aula de dança porque era forró. Aí os meninos reclamaram que não sei o que, segundo ano, aí, quando acabou a aula, eles estavam indo embora, aí o menino falou assim... Eu pesquei a conversa... Pô, bicho, pra mim deu certo porque eu aprendi a dançar forró, mas eu peguei a manha assim, eu acho que o dia que eu chegar eu vou dançar. Poxa, é isso. É isso! Eu estou aqui pra isso. Eu estou aqui pro menino viver cotidianamente o que ele aprende aqui. Então, eu acho que, quando acontece esse tipo de coisa, quando a menina chega e fala que jogou xadrez lá na casa da família dela porque aprendeu o xadrez na aula, quando o menino fala que teve uma gincana na família que ele propôs um monte de atividade que ele fez na Educação Física, eu acho que, quando ele leva pra vida dele a coisa que é da escola, que é da Educação Física, é que a gente traz como conteúdo, eu acho que isso dá muita satisfação (Prof. 5).

Paralelamente a esse desafio de tentar desenvolver projetos de ensino que garantam aos estudantes o acesso a uma pluralidade de conteúdos, os professores relatam que uma das principais dificuldades encontradas nos meses e nos anos iniciais da docência é saber como gerir o tráfico de influências, os tipos de interação humana e as formas de comunicação que seriam próprias do ambiente de ensino da EF. Vejamos abaixo dois relatos nessa direção:

Totalmente diferente pelo espaço, a questão de você trabalhar numa quadra, no fim das contas, é você ir pra um espaço aberto, conversar com a quantidade de alunos num espaço muito mais amplo do que uma sala é muito diferente. Você ter certo controle dos alunos dentro de uma quadra é completamente diferente do que dentro de uma sala. Sua voz, seu desgaste físico é muito maior numa quadra do que numa sala de aula, e até o seu planejamento, você ter o seu planejamento numa quadra é difícil; então, por exemplo, quando você vai explicar alguma coisa, eu levo minha pasta, e é muito difícil eu tenho que deixar a pasta na arquibancada e voltar e explicar alguma coisa, e os meninos estão jogando lá no meio, então não dá pra eu ficar no meio com a pasta; é muito diferente você ter a sua mesa dentro de uma sala de aula, e até porque a voz vai embora numa quadra. A motivação dos alunos é diferente, então a aula de Educação Física ela é muito prazerosa. É diferente de alguma aula; não sei, talvez, eu particularmente não sou muito fã de 
Matemática, então pra mim uma aula de Matemática não é a mais prazerosa do mundo, e os alunos sentem isso, quando eles estão na quadra. Sim, muito mais fácil, você lidar com os alunos, são muito mais abertos para conversar com você, do que está legal do que não está. 'Olha, professor, essa aula não foi bacana'. Até eu dou essa margem pros alunos de, eu falo: Olha, gente, e aí, o que deu certo, não deu, por que que não deu. E aí isso é bacana, coisa que, dentro de uma sala de aula, essa rigorosidade, você está sentado, ter que fazer, isso aí eu acho que os alunos sentem muito, quando vão pra quadra. Eu acho essa diferença (Prof. 3).

Então, os outros professores não, eu acho que eles conseguem ter noção do todo mais fácil assim. Lógico que tem uns que vão estar mais quietinhos, vão estar desenhando durante a aula, outros que não vão conseguir fazer, mas eu acho que é mais fácil de eles controlarem, eu não sei se é porque é o início mesmo da docência, mas eu tenho muita dificuldade de controlar isso; então, quando eu pego a minha turma de 46 alunos, eu não consigo ter noção de todo mundo, não consigo falar de todos. Porque são tempos diferentes, é uma aula que são duas vezes só na semana. Tem turma que tem 46 alunos. Então, duas, e turma de 46 alunos, com uma aula na semana pro ensino médio só tem uma aula na semana, é difícil porque tem um professor de Matemática que tem cinco aulas na semana; então, a relação daquele professor com aqueles alunos é diferente (Prof.6).

Nos relatos dos professores, o que nos causou surpresa à primeira vista é 0 estranhamento a um contexto de ensino que deveria ser tomado como algo mais familiar para um professor de EF já graduado. Isso nos remete inevitavelmente aos abismos existentes entre a formação inicial e a realidade concreta de trabalho dos professores na escola. Aqui, neste caso, mostram-se incipientes os conhecimentos e as habilidades na gestão de classe (domínio de turma), que ajudem os professores a construir uma ação mais consciente do que se faz no interior desse ambiente de ensino e de desenvolver imagens mais realistas da docência em EF. Diante desse quadro, parece-nos essencial que os programas de formação inicial possibilitem experiências de aprendizagem que sejam válidas e representativas das condições reais de trabalho em EF e que reconstruam a própria compreensão profissional mediante experiências de confrontação com essa realidade singular.

Além das dificuldades de lidar com a ecologia da sala de aula da EF, os professores alimentam determinadas crenças relacionadas ao que seria específico à experiência de ensino na EF e, por via de consequência, ao que seria próprio da intervenção pedagógica de um professor dessa disciplina. Tais crenças sustentam a autopercepção de que exercem o papel de um professor, seja no reconhecimento de similitudes com relação ao trabalho dos demais professores da escola, seja na identificação de papéis ímpares aos professores de EF, dado 0 caráter singular do conhecimento que ensinam.

No que diz respeito às crenças dos professores, definimos como um reservatório de valores e ideias preconcebidas sobre as quais os docentes se apoiam para agir e justificar suas ações. Sua legitimidade está no fato de deterem alto grau de generalização, não contestáveis por não necessitarem de comprovação e justificativa por meio de argumentos e/ou experimentação rigorosa. As crenças dos professores são geralmente compartilhadas, estáveis, resistentes à mudança e são frequentemente associadas a um estilo muito específico de ensino (VAUSE, 2009).

As crenças que os professores sustentam sobre si mesmos, a escola, o trabalho e os estudantes são importantes porque, juntamente com os conceitos que incorporaram na formação inicial, atuam de forma a conformar formas de inserção e desenvolvimento profissional. Há uma 
variedade de crenças que sustentam as decisões e as ações dos professores. Os professores têm crenças sobre o que significa ser professor, sobre o que e como ensinam, sua capacidade de ensinar bem e sobre a faixa etária dos alunos. As crenças servem de adaptação ao universo escolar, e através delas os professores interpretam o cotidiano na sala de aula, os objetivos, os problemas, os novos conhecimentos e as experiências. As crenças motivam e guiam 0 comportamento e as ações dos professores, incluindo a decisão de permanecer ou não na profissão (PAJARES, 1992).

Seguem relatos de dois professores sobre algumas de suas crenças acerca das singularidades do seu trabalho na escola:

A motivação dos alunos é diferente, então a aula de Educação Física ela é muito prazerosa. É diferente de alguma aula, não sei talvez, eu particularmente não sou muito fã de Matemática, então, pra mim, uma aula de Matemática não é a mais prazerosa do mundo, e os alunos sentem isso, quando eles estão na quadra. Sim, muito mais fácil você lidar com os alunos, são muito mais abertos para conversar com você, do que está legal do que não está. 'Olha, professor, essa aula não foi bacana'. Até eu dou essa margem pros alunos; eu falo, olha gente, e aí, o que deu certo, não deu, por que não deu. E aí isso é bacana, coisa que, dentro de uma sala de aula, essa rigorosidade, você está sentado, ter que fazer, isso aí eu acho que os alunos sentem muito, quando vão pra quadra. Eu acho essa diferença (Prof. 3).

Eu acho que é diferente. Eu acho que os desafios, ambos passam por grandes desafios a qualquer docência, mas eu reconheço que é diferente. Os desafios são diferentes e... Então, eu acho, começando pelo trabalho que a gente faz pro corpo, no sentido, eu tenho aluno que é excelente dentro da sala de aula, mas, no recreio e na minha aula, ele se transforma. Então, é algo diferente porque eu estou lidando com o corpo em movimento. Eu estou... se afloram várias coisas em um aluno que, às vezes, dentro da sala de aula não... Sentimentos de tristeza, de muita alegria, problemas dentro de casa que se expõem num jogo. Então, com o diálogo, você vai descobrir que tem algo muito atrás. Não foi a bolada. Ela não está chorando por causa da bolada. Ela está chorando por outras questões que culminaram às vezes ali. Então, eu acho que a Educação Física é singular porque ali na quadra acontecem diversas situações num jogo, independente do conteúdo, na relação com o outro, que possibilitam conhecer 0 aluno por outras questões da vida dele. Me coloca uma responsabilidade muito grande, que eu não estou ensinando futebol apenas. Uma responsabilidade de educar, de formar e entender que o nosso olhar pros alunos tem que ter um olhar cauteloso ali na hora do jogo, na hora da atividade... não estou trabalhando só como corpo. Como muitos ainda acreditam ou acham que é. Os professores, os outros regentes, acham que pode ser. Então, acho que é uma responsabilidade e é muito bom poder contribuir para essa formação singular das outras (Profa. 4).

Nesses relatos, pode-se verificar que os professores alimentam determinadas crenças que contribuem para demarcar diferenças entre a sua intervenção pedagógica daquelas operadas pelos docentes de outras disciplinas da escola. A primeira delas diz respeito ao fato de que na Educação Física os professores teriam maior acesso a informações sobre a emoção e o comportamento dos alunos. Isso em razão de que a aula de EF proporcionaria vivências relacionais mais intensas, dadas a maior de frequência de atividades em grupo e do maior contato corporal entre os alunos, o que proporcionaria aos docentes maior sensibilidade e capacidade para intervir em aspectos à educabilidade humana (valores, emoções, habitus). Parece predominar nessa constatação o fato de que professores de disciplinas com baixo status acadêmico tendem a demarcar sua identidade como mais ligada aos aspectos gerais do 
ensino (formação de valores, comportamentos) do que aos específicos (ensino dos conteúdos específicos).

Um segundo dado importante é que a EF vem associada a uma vivência de maior prazer, comparativamente às disciplinas de caráter teórico-conceitual. Nessa linha de compreensão, tal crença revela que um bom professor de EF é aquele que seria capaz de garantir um processo de ensino-aprendizagem que seja, ao mesmo tempo, similar ao que se faz nas outras disciplinas (transmissão de conteúdos) e singular porque, nas aulas de EF, se garantiria aos alunos vivências de prazer e alegria, dado o pretenso caráter sempre prazeroso do movimento corporal.

Tal crença acentua a centralidade do retorno (sempre positivo, é claro) dos alunos para uma experiência gratificante com a profissão. Essa leitura dos professores, passível de crítica e eivada de contradições, além de atuar de maneira significativa na interpretação da vida na sala de aula, na leitura sobre as motivações/necessidades dos estudantes e na definição de objetivos pedagógicos a atingir, parece ter um efeito significativo na produção ou não de recompensas intrínsecas que contribuem para alimentar o compromisso com o trabalho e o desejo de permanecer na profissão.

\section{CONSIDERAÇÕES FINAIS}

Não obstante reconhecer que os professores iniciantes de EF vivem os mesmos dilemas profissionais dos professores iniciantes das demais disciplinas escolares (solidão, estresse, conflitos com os alunos, invisibilidade, falta de apoio institucional, condições inadequadas de trabalho, carreira pouca atrativa e salários indignos), há que se reconhecer que a experiência de inserção profissional não pode ser tomada como objeto de igual consideração para os professores das diferentes disciplinares escolares.

Os achados de nossa investigação mostram que o pertencimento a um determinado campo disciplinar é um elemento importante a considerar para análise de diferentes trajetórias percorridas pelos professores no período da iniciação à docência, já que definem modos cruciais de ser professor, de como desenvolver o trabalho e de como esse trabalho é percebido por outros.

Dentre as formas de empenhamento e entrada na profissão, próprias à experiência de inserção profissional dos professores de EF pesquisados, destacam-se as seguintes: as formas singulares de controle e regulação do conhecimento dessa disciplina; necessidade de harmonizar conflitos com os alunos ante o desejo desses de que o ensino dessa disciplina se resuma não apenas ao tratamento de um conteúdo de ensino e uma extensão, sem mediações, das vivências que eles têm com as práticas corporais fora da escola; dificuldades de lidar com o ensino nas condições ambientais singulares da sala de aula da $E F$, lugar esse que se difere do modelo de unidade celular de classe hegemônico e enfrentamento de situações relacionadas ao déficit de legitimidade acadêmica da EF, em especial às baixas expectativas da gestão escolar e dos estudantes em relação ao ensino que opera na sala de aula da EF.

Sobre esse último ponto é importante ressaltar que a experiência de inserção profissional de professores de disciplinas tidas como de "segunda classe" é um dado a ser considerado em análises que tratam dos processos de desinvestimento profissional precoce e abandono da profissão. Isso porque o mandato docente afeta também o seu status devido 
à hierarquização das matérias ensinadas. Os professores em geral perseguem objetivos e se esforçam para respeitar os programas de ensino, mas estes não têm o mesmo valor para os alunos, os pais e os próprios professores. Desse modo, as hierarquias entre os sabres escolares se traduzem numa hierarquização profissional da identidade dos professores, que remete a práticas pedagógicas parcialmente diferentes de acordo com a motivação dos alunos, as pressões dos pais e a percepção dos colegas. 0 mandato de trabalho dos professores se diferencia segundo uma lógica de poder simbólico das disciplinas ensinadas, um poder herdado, ou apropriado por aqueles que as lecionam (TARDIF; LESSARD, 2005).

Esse contexto situado de trabalho, se por um lado pode reforçar aspectos mais diretamente ligados à experiência sofrida da sobrevivência (estresse, solidão, desilusão, invisibilidade), por outro, pode potencializar aspectos da descoberta da profissão e da aprendizagem docente, na medida em que pode avivar as experiências de socialização profissional, via alargamento de conhecimentos da cultura escolar, dos alunos, dos conteúdos de ensino e de seus aspectos didáticos.

Reconhecer, incluir e apoiar diferentes trajetórias de docentes iniciantes parece ser um dos desafios a serem enfrentados em ações e políticas de retenção de novos professores. A compreensão do "ficar" na profissão docente precisa ser urgentemente redefinida (COCHRANSMITH, 2006). Este "ficar" tem de incluir vários caminhos de progressão na carreira e deve se tornar uma referência fundamental à produção de políticas de formação, indução e desenvolvimento profissional dos professores, bem como objeto de preocupação da comunidade acadêmica, dos gestores da educação pública/privada e da comunidade escolar, de forma a reconhecer, a valorizar e a apoiar as diferentes formas de ser e de atuar na docência.

\section{REFERÊNCIAS}

BETTI, Mauro. Educação Física e sociedade. São Paulo: Movimento, 1991.

BRACHT, Valter. Sociologia crítica do Esporte: uma introdução. Vitória: Centro de Educação Física e Desportos da Ufes, 1997.

BRACHT, Valter; FARIA, Bruno A. A cultura escolar e o ensino da Educação Física: reflexões a partir da teoria de do reconhecimento de Axel Honneth. In: SANTOS, Lucíola L. C. P. S. et al. Convergências e tensões no campo da formação e do trabalho docente. Belo Horizonte: Autêntica, 2010. p. 234-248.

CARTER, Kathy et al. Processing and using information about students: a study of expert, novice, and postulant teachers. Teaching and Teacher Education, v. 3, n. 2, p. 147-157, dec. 1987.

COCHRAN-SMITH, Marilyn. Why people teach and why they stay. Bank Street College of Education: Occasional Paper Series, v. 16, p. 20-42, Apr. 2006.

FEIMAN-NEMSER, Sharon. Helping Novices Learn to Teach: Lessons from an Exemplary Support Teacher. Journal of Teacher Education, v. 52, n. 1, p. 17-30, 2001. 
FEIMAN-NEMSER, Sharon; FLODEN, Robert. E. The cultures of teaching. The Institute for research on teaching, v. 74, p 80-96, 1984.

FORQUIN, Jean-Claude. As abordagens sociológicas do currículo: orientações teóricas e perspectivas de pesquisa. Educação e Realidade: currículo e política de identidade, v. 21, n. 1, p. 87-98, 1996.

HUBERMAN, Michael. O ciclo de vida profissional dos professores. In: NÓVOA, António (Org.). Vida de professores. Porto: Porto Editora, 1992. p. 31-62.

KELCHTERMANS, Geert; BALLET, Katrijn. The micropolitics of teacher induction: a narrativebiographical study on teacher socialization. Teaching and Teacher Education, v. 18, n. 1, p. 105-120, 2002.

LESHEM, Shosh. Novices and veterans journeying into real-world teaching: how a veteran learns from novices. Teaching and Teacher Education, v. 24, p. 204-215, 2008.

LINHALES, Meily. A. Trajetória política do esporte no Brasil: interesses envolvidos, setores excluídos. Belo Horizonte: UFMG, 1996. 266 f. Dissertação (Mestrado em Ciência Política) UFMG, Belo Horizonte, 1996.

PAJARES, Frank. Teachers' Beliefs and Educational Research : Cleaning up a M. Review of Educational Research, v. 62, n. 3, p. 307, 1992.

TARDIF, Maurice; LESSARD, Claude. 0 trabalho docente: elementos para uma teoria da docência como profissão de interações humanas. Petrópolis: Vozes, 2005.

VAUSE, Anne. Les croyances et connaissances des enseignants à propos de l'acte d'enseigner: Vers un cadre d'analyse. Recherche, v. 66 , p. 1-33, Avr. 2009.

VEENMAN, Simon. Perceived problems of beginning teachers. Review of Educational Research, v. 54, n. 2, p. 143-178, 1984.

ULVIK, Marit; SMITH, Kari; HELLEVE, Ingrid. Novice in secondary school - the coin has two sides. Teaching and Teacher Education, v. 25, n. 6, p. 835-842, 2009.

VONK, Johan. Mentoring Beginning Teachers: Development of a Knowledge Base for Mentors. American Educational Research Association, v. 1, p. 1-26, Apr. 1993.

Apoio:

Esta pesquisa foi iniciada em 2012, finalizada no ano de 2014 e contou os financiamentos da 